\title{
Haitian Resiliency: A Case Study in Intermittent Infrastructure
}

\author{
Donald J. Patterson \\ Department of Informatics \\ Department of Computer Science \\ University of California, Irvine \\ Irvine, CA, USA \\ djp3@ics.uci.edu
}

\begin{abstract}
In 2010 Haiti experienced a catastrophic earthquake that destroyed a substantial amount of infrastructure in the capital of Port-auPrince. Limited national resources and widespread poverty ${ }^{1}$ have made the rebuilding slow and piecemeal. Five years later that infrastructure is still unevenly repaired and maintained. Nevertheless, the Haitian people have, by necessity, continued to adapt in order to take care of day-to-day activities. Based on a field visit, this paper describes some of the ways that infrastructure has re-emerged, gives examples of how people deal with the alternate infrastructures and discusses what these lessons entail for how the developed world frames infrastructure in the face of similar challenges caused by global energy shortages.
\end{abstract}

\section{INTRODUCTION}

On January 12th, 2010 at 4:53pm Haiti experienced a magnitude 7.0 earthquake centered approximately 15 miles from the capital of Port-au-Prince. Major earthquakes like this one have occurred approximately once every 100 years in Haiti. But in modern times, Port-au-Prince is a crowded city and as such the human cost of this most recent earthquake was particularly high. Between 100,000 and 316,000 people were killed (official estimates leaning higher), and a comparable amount of people were injured. This natural disaster was devastating to both the human and the built infrastructure of Haiti. As a result of damage to homes and buildings over 1 million people were displaced [27]. Many of the displaced people were necessarily relocated far from the city center to places where space was available and shelter could be constructed, but where jobs and infrastructure were missing.

As part of a short trip to Haiti in February 2015, I had the opportunity to interview Haitians, relief workers and missionaries involved in community development and to visit many sites of displacement and rebuilding. My interest was in evaluating the ways in which earthquake survivors dealt with broken, or more accurately, intermittent infrastructures. The environment 5 years after the earthquake, presented itself as a viable academic field site for evaluating the implications of "Collapse Informatics". Collapse Informatics is characterized "by the study, design and development of sociotechnical systems in the abundant present for use in a future of scarcity." [23] In the literature introducing this concept [22, 23, 24],

\footnotetext{
${ }^{1} 204$ out of 228 nations in GDP per capita [2]
}

the expected proximate cause of "the collapse" is not envisioned to be a natural disaster, but rather a long energy descent caused by dwindling non-renewable resources such as fossil fuels [8]. The relevant similarity however is that the results are the same: failing, intermittent infrastructures that are too expensive to keep operating at continuous levels of availability. Therefore, the research question that the Haitian earthquake experience can help to answer is, what can communities with well-maintained infrastructures learn about preparing for the effects of the energy descent? As information technologists in particular, how should we respond now, while we have abundant bandwidth, power, and computational resources? The following is a report, motivated by these concerns, of how intermittent infrastructure has impacted everyday life in a portion of Haiti.

\section{RESEARCH CONTEXT}

The opportunity to go to Haiti came to me through my involvement with a church that has sent several other teams to Haiti over the last 3 years $^{2}$. The focus of each trip has been slightly different but has included educational activities with school children, relief work in the form of water filter distribution, training workshops for teachers, and community development. In each case, a 25-year resident of Haiti who was affiliated with the church denomination's missionary organization hosted the trip. His income has been primarily supplied by a large number of private donors, churches and organizations who voluntarily contribute money and resources to the work that he does. Additionally, hosting short-term trips like ours generates a small amount of income in the form of fees for housing, interpreters and associated travel services. He and his wife were present during the earthquake and subsequent rebuilding efforts: The residential facility (originally a large private home) that we stayed at was a makeshift hospital for several weeks after the disaster.

The trip opportunity coincided with an online course that I was co-teaching titled "Global Disruption and Information Technology" This course's focus was on educating University of California students on the challenges to global well-being caused by declining energy resources, global climate change and the effects of unsustainable practices with a particular emphasis on mobilizing students to make changes in their local communities. In addition to supporting the work of the mission team, as an instructor for the class, I also saw this as an opportunity to study the sociotechnical response to infrastructure degradation and the ways that people com-

\footnotetext{
${ }^{2}$ Newport Mesa Church
} 
pensated. Over the course of the visit I was able to film, process and deliver a video lecture back to the class once every other day ${ }^{3}$.

My interest in the role of technology in the developing world began with a similar trip that I took in 2007 to Africa in which I intended to see how mobile technology could be used to help humanitarian relief for children whose parents had died of HIV/AIDS. During that trip I was confronted with the differences between what Africans were concerned about and what I, as a Western academic was concerned about. For example, while micro-finance, women's rights, clean water access, and mosquito nets filled our minds as grant writers, the people on the ground were much more concerned about the dangers posed by snakes. This prompted much soulsearching about "helping" in the face of cultural differences [17] and reflected broader thinking in the HCI community about postcolonial computing [11]. As a response, this case study was framed as trying to learn from Haitians rather than trying to fix problems for them, at least in the short-term.

\section{INTERNATIONAL RESPONSE}

Following the earthquake, the United States government's official international aid agency, USAID, participated in recovery and response efforts. USAID characterizes its support in 3 nonexclusive ways: Health and Basic Services, Food and Economic Security, and Infrastructure and Energy. With respect to the latter, it reports that it housed 328,000 displaced Haitians through a variety of approaches, including transitional shelters, repairs and the building of 900 permanent new homes. They removed 2.7 million cubic meters of earthquake rubble, approximately 36 percent of the total removed. They rebuilt and/or refurbished 5 electrical substations and introduced natural gas stoves to replace charcoal, in order to reduce demand for wood and improve air quality. A number of initiatives also provided for administrative transparency and reduced corruption in government and finance [25].

The European Union's Humanitarian Aid and Civil Protection Department (ECHO) also responded and continues to respond with aid. In the 3 years following the disaster the EU spent $€ 91$ million and committed to doubling the rate of development spending for the 7 years from 2014-2020. The initial focus of ECHO was on returning displaced people; promoting water hygiene, sanitation and cholera management; and on building resilience against future disasters [3]. Notably, as a point of overlap with this redevelopment work, the post-peak Transition Town movement also focuses on the capacity for resilience among their communities in the developed world [10]. Both ECHO and the Transition Town movement orient their efforts by assuming continued future challenges rather than requiring future growth.

Many other countries, individuals and NGOs [27] provided aid as well, including Canada [9], the UN [7] and Venezuela [12]. Notably, the aid itself complicated the relief efforts as evidence has been mounting that UN relief workers were the source of the first outbreaks of cholera in Haiti in the last 150 years [15, 18, 20] and the focus of numerous reports of sexual abuse against Haitian children [26]. Locals did not mention the former, but were very upset about the latter. Furthermore, the Venezuelan aid has taken on a complicated form.

Venezuela has a partnership with Haiti in which it supplies the majority of Haiti's fuel via its Petrocaribe program that started several years before the earthquake. Venezuela allows Haiti to pay

\footnotetext{
${ }^{3}$ Class video playlist
}

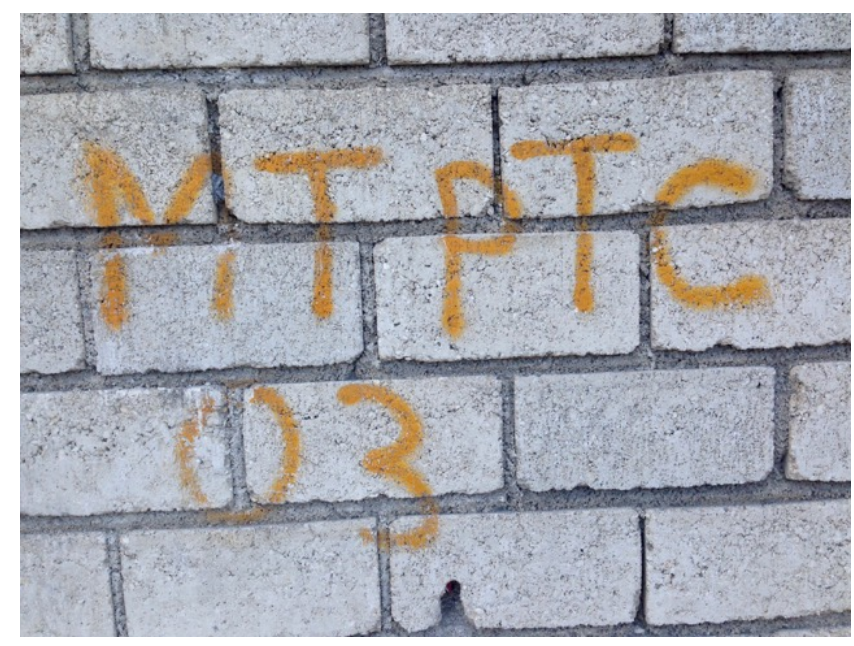

Figure 1: MTPTC paint outside of a Haitian building. The paint color indicates the assessment of the building's structural stability.

part of its fuel import bill immediately and allows the rest to be owed as a low-interest loan (1\% over 25 years) [5]. Additionally a portion of the immediate payment can be made in agricultural products, reducing the need for hard currency. Following the earthquake, Venezuela immediately forgave Haiti's existing \$400 million fuel loan, a magnanimous gesture [12]. As Haiti began its recovery, selling Venezuelan fuel to Haitians became a very immediate source of income for rebuilding. Haiti used only a portion of the sales to pay back Venezuela, the other portion, the part that Venezuela treated as a loan, could be used to finance government projects. These additional funds however, were and are difficult to track and are susceptible to various types of corruption [5]. The new Olympic Training Center is cited as an example of one such suspicious project [13]. We saw this first hand because one of our projects was to deliver water filters to the settlement across the street, Canaan. Currently the schools and families there must purchase potable water for themselves and their students. The juxtaposition of extreme poverty next to a very large, brand-new, but empty, sports complex was disconcerting. The water filters cost approximately $\$ 40.00$ wholesale. The Olympic Training Center cost $\$ 18$ million [15].

Days before my visit, there were protests in Port-au-Prince against existing fuel prices [16]. Despite a 50\% drop in global fuel prices [21], Haiti's national fuel price remained high. This could clearly be explained by the arrangement with Venezuela, which allows the Haitian government to capture all the excess profit as windfall. Keeping prices high serves to increase funds for the government as the underlying price of the fuel drops. Aside from concerns about corruption, it also systematically impacts the willingness of the government to invest in infrastructures that are fuel efficient, let alone fuel independent, because any reduction in fuel usage reduces available funds to the government. Haiti's ability to continue to benefit from this arrangement is increasingly under stress as Venezuela's ability to maintain the Petrocaribe program is faltering $[4,19]$.

The impact of the aid was difficult to see on the ground during my visit. There was remarkably little earthquake rubble remaining, and there were a few small dense developments of new perma- 


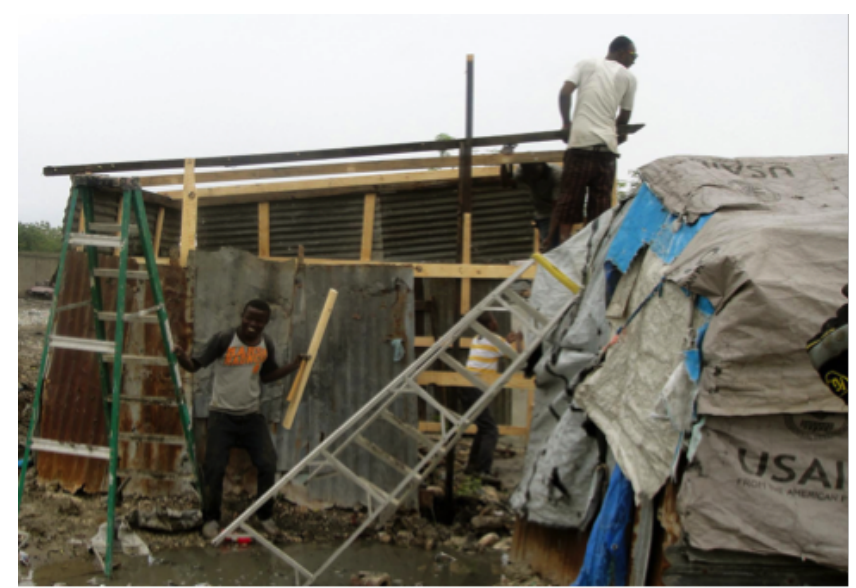

Figure 2: Relief workers repair the roof of a home in Cite Soleil. USAID material such as on the right was commonly incorporated into homes in the poorest areas (3/31/15 Courtesy of Bill Smith).

nent homes oddly placed in the middle of nowhere. Both provided evidence supporting USAID's development claims. I saw many buildings that had the code "MTPTC" spray painted on the outside (See Figure 1). This was the indication from engineers about the condition of the building. Red paint meant that the building was dangerous to enter. Yellow meant that repairs needed to be made. Green meant that the building was safe. I didn't see any remaining red markings, but electrical wire support poles that were falling over were labelled with green paint.

There was some thriving industrial activity. On one trip we visited the SONAPI Industrial Park from which hundreds of workers streamed out every evening creating significant congestion and a market for private taxi's ("tap-taps"), and street vendors. Down the road was a large operational power plant, and several warehouse areas, visible but securely protected by 10-15 foot high concrete walls and barbed wire. The workers leaving the industrial plant were dressed professionally and better than other foot traffic. The atmosphere was busy and lively. Conversations on the topic of the plant with other Haitians, who were notably not employed by the plant, revolved around the unacceptably low wages that the plant paid.

It was very common to see USAID branded material that was incorporated into shelters as walls and roofs (See Figure 2). We saw UNICEF labeled cars outside of a small restaurant and one transport truck filled with UN peacekeepers, although there was no peacekeeper presence in any of the areas that we spent time. A construction site for a UN facility was under active development near the airport, although its role wasn't clear.

\section{INFRASTRUCTURES}

Infrastructures can be defined as "persistent socio-technical systems over which services are delivered" [14]. Using this definition allows for many different kinds of things to be considered as infrastructures including utilities, as expected, but also less obvious things such as education and gated communities. In fact, the number of things that could be considered as infrastructures in this way is enormous. Nevertheless, it is a helpful lens through which to frame the study of collapse informatics because it organizes ele-

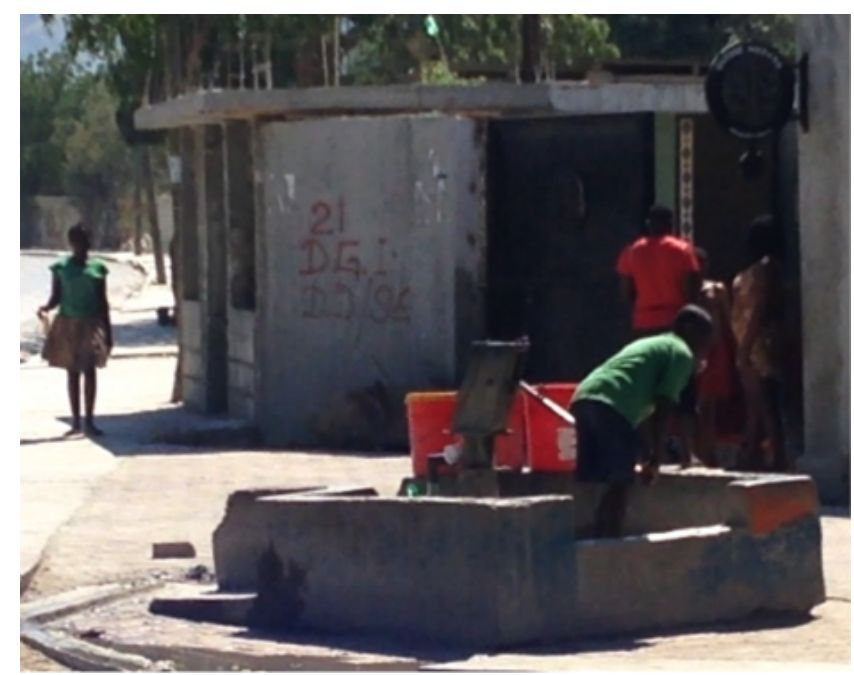

Figure 3: Hand-pumped water well in Port-au-Prince neighborhood

ments of complex systems into coherent concerns that can be studied separately. Infrastructures are noted for their invisibility however, and so are easy to ignore despite being critical for societal functioning [14]. In what follows, I discuss some of the infrastructures that were particularly visible to me as an outsider.

\subsection{Water}

The water infrastructure was a persistent concern throughout all facets of the trip. Clean water is not taken for granted in Haiti. The cleanest water was prioritized for drinking, then cooking, then bathing, then cleaning/washing. On the street, vendors sell small sealed bags of water for a low price ( $\$ .10$ for $\sim 12 \mathrm{oz}$.). This was the most basic source of safe water. In order to consume the water, a corner of the bag is cut or torn. This water is clean, although the outside of the bag is not. School children received a daily allowance of one bag and used water bags were a common sight lying in the street.

Neighborhoods had community wells that were accessed by metal hand pumps (See Figure 3). This water was commonly transported in 5 gallon buckets. The hardware was standardized and reflected systematic development. Generally the groundwater in the city was not safe for drinking and a financial trade-off often had to be made between the cost of water, its source and its intended use. Our interpreter, when living in the city, would purchase all his water for drinking, cooking and bathing. Further from the city, some groundwater wells were safer and some delivered "salty" water that weren't even used for drinking in extremis, although the water wasn't "sea-water" as might be expected from the description. Far out in the countryside, water was taken directly from surface streams.

In our host's residential facility, water was carefully managed. A single guest was estimated to need 30 gallons day. A large buried cistern ( $\sim 3200$ gallons) behind the house collected both piped city water and rainwater. City water was delivered on an irregular basis and wasn't safe enough to drink. Rainwater was collected from the roof of the facility and fed through a network of exposed PVC pipes to the cistern. Often, the rainwater collected from the roof of the building would be more plentiful than that delivered by the city. In 


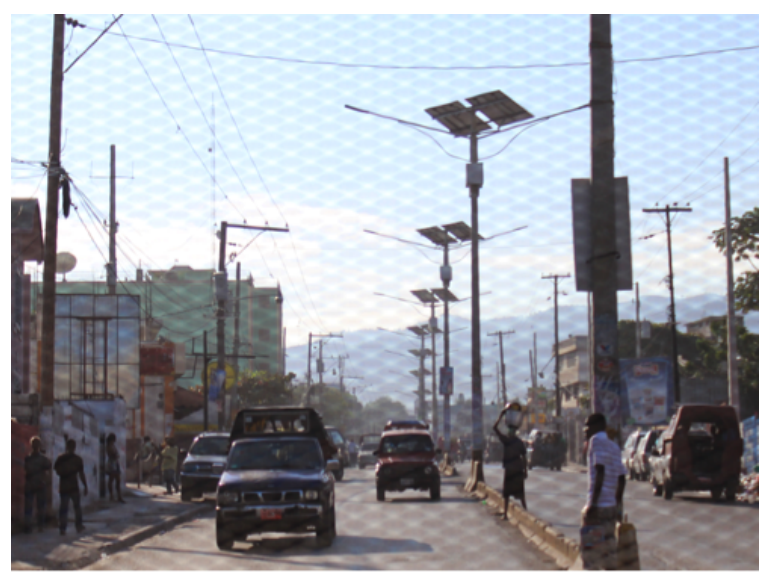

Figure 4: Solar-powered street lamps in Port-au-Prince

particularly dry periods, when neither city water, nor rainwater was available, our host would order a truck to deliver a cistern's-worth of safe drinking water.

An electric pump pumped this cistern water to a smaller cistern ( 1500 gallons) on the roof of the building through a second series of exposed PVC pipes. The roof actually had 2 cisterns, but one was no longer in working condition. Once the water was on the roof, it was then gravity fed to the different points of delivery in the house. The kitchen and bathroom sinks were supplied from the roof, as were the showers and toilets. There were no hot water heaters in the facility.

The water that arrived in the kitchen was used directly out of the tap, with some bleach, for dish washing. Additionally the tap water was run through a detached water filter (the same kind we delivered to the residents of Canaan) to use for cooking. The water filter was used for removing particulates and microbes and was based on technology developed for kidney dialysis machines.

Water that was used for drinking came from a service that delivered office-water-cooler style bottles. In fact, the company was the same as one in the U.S., Culligan. During the day when we were travelling in Haiti, we carried personal water bottles that we refilled from these water coolers in the morning as well as a large portable cooler that served as a backup supply.

\subsection{Electricity}

Electricity in the residential facility was supplied from three different sources. Generally, every evening from $10 \mathrm{pm}$ to $6 \mathrm{am}$ the city power grid supplied power to the home. The people I spoke to didn't know the exact reason for this timing, but it was speculated that it was to allow air conditioning and security lights to operate during the night. Although the city power was more regular than the city water, it didn't always start and stop on time and was even more unreliable during rain. It wasn't clear if that was a proactive concern about exposed wiring, or a reactive response to short-circuits resulting from water intrusion. During the world cup soccer games, grid power was generated and delivered so that people could watch them on television. Public streetlights were used as indicators of the state of the city power.

While city power was operational, in addition to its immediate use, it charged a bank of batteries located in each room of the house. There were approximately 4 banks of 8 car batteries each. Each bank had it's own inverter for converting AC power to DC power and vice versa. During the day, when city power was off, the battery banks operated in lieu of city power. The primary need for power in the home was for lights, refrigeration and small electronics. With careful management, the battery banks could last from 6 am to $10 \mathrm{pm}$.

If electricity was needed and neither battery power, nor city power was available, a diesel generator was also on the property that could be used to power the home and charge the batteries. The diesel generator was not a common feature of Haitian homes and was somewhat unique to our facility. Several times during our stay power would turn off unexpectedly and a decision had to be made about whether to turn on the generator or not. Doing so entailed a cost in fuel, noise and air quality (due to exhaust).

Unsurprisingly, individual houses were responsible for paying electricity bills for the electricity that was delivered to the building, but it was also common for electricity to be "stolen" by others who tapped into the wiring downstream of a meter for a particular facility. This was generally known to be happening by owners, but it was ignored as it was seen to be an acceptable way to take care of one's neighbors.

There was not widespread use of alternative sources of electricity in Haitian infrastructure. The one exception was the installation of public street lamps that were solar powered (See Figure 4). These were introduced after the earthquake and each had a pair of solar panels, batteries and high-power LED lights. They were common throughout the city and were even found in very remote areas of the countryside.

In one case in a remote village a street lamp that was installed on a soccer pitch had had it's solar panel dismantled. The panel (or an equivalent one) was about $1 \mathrm{~km}$ down the road in a roadside stall. It was attached to a power strip that was charging phones for a fee in an environment which otherwise had no source of electricity. Some Haitians had personal portable solar panels that were also used to charge phones.

\subsection{Security}

Residential security was a concern in the facility that we were staying in. Ten-foot high walls surrounded the compound with barbed wire on the top. Vehicle entrance to the facility was through a large metal sliding door that was never left open or unlocked. Embedded within the sliding door was a smaller door for pedestrian access. Leaving the compound was not done casually. Unknown people were not allowed into the compound with the exception of women with children who were informally treated by a nurse on staff. During the day, walking through the neighborhood was safe, but travelling by foot or vehicle after dark was avoided completely.

A local Haitian was employed as a watchman during the day and was responsible for maintaining the area outside of the building, but within the walls. He also provided access for vehicles and service providers and performed light maintenance. A large German Shepherd guard dog was present outside 24 hours a day.

The primary security threat was from robbery, both opportunistic and planned. There wasn't a specific concern about firearms or weapons although it was not unheard of for there to be gun fire within a few blocks of the home. The building itself had bars on all the windows and another locked iron gate blocking the entrance to the foyer. Inside the house, several additional barriers isolated portions of the home with gates and heavy locked doors and had to be regularly unlocked and locked. The home had had several break-ins over time, and even recently. One planned robbery involved gain- 
ing access directly to the second story of the home through some extraordinary acts of climbing and a second opportunistic breakin occurred from an individual gaining access from the street and "wandering" into the interior of the home. The former was addressed with second story bars being placed on windows and the later with closer attention to security practices. While it was generally known that Americans were staying in the compound, this kind of security overhead was endemic to all but the poorest and remotest of neighborhoods. When cost made barbed wire prohibitive to install, glass shards cemented onto the top of walls, secured other houses in the area.

\subsection{Communication}

Cellphones were endemic in Haiti. As is the pattern in many poor countries, wireless coverage leap-frogged the development of reliable wired connections. As such, the preferred method of obtaining Internet access was through cell-phone tethering, but the cost of this kind of access was high. In Port-au-Prince homes, a special router, analogous to a cable modem, could be purchased that connected to an Internet Service Provider (ISP) through long-range omnidirectional wireless connections. A laptop (or any Wi-Fi enabled device) would connect to the router that acted as a Wi-Fi access point and data packets would be forwarded to the ISP. This router was an upgrade from a previous generation that used a directional antenna. One such antenna remained on the roof of our facility, just in case. Unfortunately, the wireless connection suffered from heavy interference. During the evening, congestion from using the shared wireless channel would increase round trip packet times to the U.S. to the order of seconds. Even the simplest online tasks were prohibitively difficult during these periods. Additionally, when raining, connectivity would fail, as the atmospheric conditions would inhibit connections to the ISP.

Local Haitians relied on pervasive cellphone connections to access data services and were heavy users of mobile phone technology. Both feature phones and Android smartphones were observed being used and Haitians are regular users of text messaging, Facebook, email and chat applications. Heavy uses of online bandwidth such as videos were avoided due to their cost.

Network connectivity was available everywhere we went however. We could obtain high quality Internet in some very remote locations. Even where people were washing clothes in remote mountain streams and using donkeys for transportation they were using cell phones. We found that Facebook, in particular, was extremely well-engineered to handle intermittent low-bandwidth connections.

\subsection{Miscellaneous}

\subsubsection{Fuel}

Fuel was available from developed world style gas stations in the capital. As you travelled further from the city however, individuals would sell fuel from roadside stands in one-gallon containers. It was common to see many stands with between 10 and 20 containers as one drove between villages. We availed ourselves of their services when travelling deep into the mountains.

\subsubsection{Transportation}

We observed people getting places by foot, motorcycles and cars in town. There were few bicycles. There was no public transportation, instead colorfully decorated private vehicles, usually modified pickup trucks, called "tap-taps" would drive on routes through- out the length and breadth of Haiti. The routes were geographically consistent, but timing was not standardized. On some longer stretches, people could be seen riding on larger trucks carrying cargo. In remote areas, as fuel was more difficult to obtain and roads were rougher, donkeys were used.

\subsubsection{Farming}

The need to develop a scalable method for food production remains critical. There was very little farming to be seen anywhere. Top soil appears poor, reportedly due to erosion caused by deforestation. $50 \%$ of food and $80 \%$ of rice is imported [6]. Diets before the earthquake were inadequate with $30 \%$ of children suffering from malnutrition and appear to be as bad post-earthquake [1].

\subsubsection{Aquaponics}

One of the projects that a previous relief team had begun was an aquaponics prototype installed on our compound. This strategy of using recirculated water to simultaneously irrigate raised beds of garden crops and farm fish was being proposed as a way of providing food security to urban slums. In those locations fresh produce is scarce and expensive, and access to clean water and high quality soil was highly limited. The installation had been running for several months and was having limited success. The staff worker that was tending it had significant farming experience and the technology precluded growing indigenous root vegetables. The transferability of the technology to Haitians was an open question.

\section{DISCUSSION}

The recurring themes in all of these infrastructures was that their availability was intermittent, they were interconnected in complicated ways and they needed constant tending to be maintained.

\subsection{Interconnection, Disconnection and Rhythm}

One of the first interconnections that I noticed was between residential water and electricity. An electric pump connected the cistern in the ground the cistern on the roof. The pump was a heavy consumer of electricity such that it could only be run on diesel generator or city power. In order to maintain a flow of water in the home the cistern on the roof needed to have water in it and that in turn required electricity to move water from the ground. Electricity was only available periodically from the city and if that wasn't available it had to be drawn from the generator. The generator in turn required diesel fuel. That fuel needed to be transported by private vehicle in a 55 gallon drums from the local gas station. Electricity and fuel were required to get water.

Uploading my online videos exposed other interconnections. I would film the videos on my smartphone and process them on my laptop. Those devices needed to be charged. The electricity to do that came from the combination of sources described earlier. Once the videos were rendered they needed to be uploaded to the U.S. The network capacity to do that depended on electricity in order to power the ISP's router. It also depended on the congestion to be limited. So the rhythm that I fell into was that I would do outreach work during the day (including filming), create the films in the evening, then when city power would come on I would begin the upload of the video to the servers. The upload would start too slowly to finish, even with several days of transfer. As people went to sleep (including myself) congestion would ease and in the morning, my computer would be charged and the video would be uploaded. 


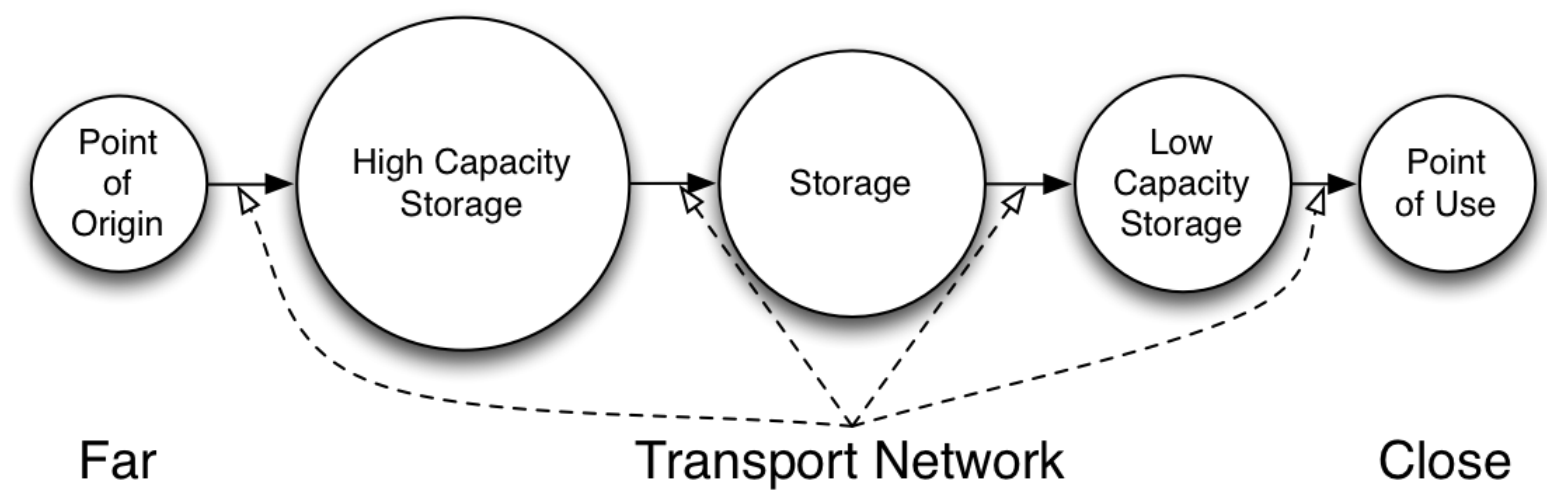

Figure 5: Haitian Infrastructures Structured for Resilience

The infrastructures didn't only interlock, however, sometimes they also worked against each other. The network connection, for example, was broken by rain. While rain was interfering with my video uploads, water was filling the underground cistern.

As a result, the interconnections and disconnections that were embedded in the intertwined infrastructures forced a structuring of routines that in turn impacted the social organization and rhythms of daily life. Because of such relationships, rain meant muddy roads and limited travel. It also meant isolation from the Internet. This made space for socializing with family and friends that were in the same house even as it was disrupting other commitments outside of the home.

\subsection{Storage}

A lot of the infrastructural resilience relied on storage and refill networks. The cisterns stored water. The underground one was larger but the rooftop one allowed for the taps in the house to work based on gravity. A full roof cistern could provide 50 person-days of water independently of fuel and electricity. When it needed to be refilled the underground cistern was its backup storage. If that emptied, the next storage further up the chain was effectively the source, whether it was the city water, the water truck, or the rain.

Similarly the electric batteries in our devices stored electricity for several hours without connecting to power outlets. The battery banks outside the rooms stored electricity backup so that when the larger infrastructure wasn't available lights could stay on and the devices could be refilled. The 55-gallon drums of diesel fuel were effectively a larger source of electricity upstream from the battery banks assuming that the diesel generator converted it to electricity. The cars (and their fuel tanks) provided access to even larger stores of gasoline that could refill the 55-gallon drums from the gas stations. Behind the gas stations were industrial fuel storage tanks. Somewhere behind that was the source, either a refinery, or perhaps an ocean going oil tanker back to a refinery in Venezuela

\subsection{Structuring Infrastructures}

These examples suggest that Haitian infrastructure resiliency could be conceptualized using components of Points of Use, Storage Cascades, Transport Network, and Points of Origin (see Figure 5). Each of these in turn were controlled and/or owned by different stake holders.

For example, in the case of the water infrastructure, the observed storage cascades were perhaps 4 deep: underground cistern, roof cistern, 5-gallon filter bucket and a cooking pot. These were all under the control of the household. More storage likely occurred upstream of the home but as infrastructure tends to be, was invisible to us.

The fuel storage cascades were several levels deep but were primarily under the control of service providers, not individuals. Within the compound there were just 55-gallon drums and the generator's fuel tank.

The storage cascades of electricity were perhaps 3 deep: diesel fuel, house batteries, and device batteries. Whether or not "diesel fuel" should be considered electricity at the very least exposes the interconnection of the storage cascades themselves.

The storage cascades of the data infrastructure that held the class videos were 3 deep, the mobile devices, the laptop and then the cloud service (YouTube).

At each point in the storage cascade there was a trade-off between capacity and distance to point of use. Higher capacity enabled efficiencies of scale. Each storage point also allowed for processing: Electricity, when stored as fuel, was converted at the generator where it was also stored. Data was converted from raw video to usable video at the laptop where it was also stored. Water was converted from rainwater to cooking water at the 5-gallon filter bucket where it was also stored.

In addition to processing at storage points, the infrastructures also interacted in the transport network. Electricity was required to move water. Electricity was required to move data. Rain was required to fill a cistern but it caused the transport network for data to be blocked (by interfering with the router). Transportation-fuel was needed to move electricity-fuel to the generator.

The decision and action required to move water along its transport network and to move electricity on its transport network was a very manual process. This could be automated by interconnecting the data infrastructures to the water or electricity infrastructures such that data would need to "be applied" to move water and electricity. This is in essence one of the promises of the Internet of Things (IoT): By effectively using sensors and actuators the IoT can control the operation of pumps and generators which move resources along infrastructures.

The potential pain points in Haiti came when one infrastructure wasn't available to make the other infrastructure work. For example, when electricity wasn't available to pump water or when fuel wasn't available to make electricity or when electricity wasn't available to power the Wi-Fi router. Although these could fairly 
be considered to be failures in the infrastructure, social structuring reacted to the breakdowns and a different kind of social infrastructure developed in response. The social infrastructure then became layered on top of the others.

\section{PROVOCATIONS}

Infrastructure resilience in Haiti has adjusted in two ways following the 2010 earthquake. First storage cascading has increased in complexity. Both by increasing the number of points of storage in the delivery chain and increasing the capacity under the control of the end-user. By increasing storage capacity, service delivery can be carefully managed for regular and/or predictable availability. This primarily reflects an increase in the amount of infrastructure under the control of the end-user. It comes at the cost of increased expertise and attention required by the end-user to manage increased complexity. As a counter point, in the absence of intermittency in the U.S., how many homeowners have gone to the trouble to make their refrigerator able to be powered by a generator?

This suggests that not only was the physical infrastructure damaged in the earthquake, but so was the political/economic infrastructure that was needed to manage the upstream storage and delivery cascades. The political/economic infrastructure is no longer able (if it ever was) to deliver services reliably. As a result, endusers are required to develop the expertise to compensate for this failure. To the degree that homeowners are willingly sharing bootleg electricity with their neighbors, end-users have not only taken control of a portion of the physical infrastructure, but have also brought the political/economic infrastructure under their control as well. While this may be more reliable and transparent, it could be less efficient as economies of scale are not leveraged.

Apart from end-users taking more control, a different trajectory to support resilience has been to reduce the entire infrastructure to a single location such that point of origin, transport network, storage cascade and point of use are all collocated. The solar powered street lamps are an example of this that was driven by the difficulty of recreating an electricity transport network post-earthquake. Aquaponics, are another example where water, solar power and an enclosed ecosystem are merged to create and deliver food at a single location. Notably however, this trajectory has the potential to cause greater disruption to the political environment by changing the points of control embedded in the infrastructure. For example, a complete rejection of fossil fuel's existing point of origin in favor of solar power would threaten the funding of the Haitian government and its relationship with Venezuela.

Finally, this conceptual framing, and these examples, allow for some provocative thought experiments. What would happen if aquaponics made too much food for one point of use? What would it look like if more points were developed in the storage cascade for data? Does the IoT actually offer sufficient benefit to justify coupling the data network and many of the other service transport networks? What would happen to the fuel network if electric vehicles were introduced? What if those electric vehicles had batteries that also functioned as part of the storage cascade of electricity?

\section{References}

[1] The World Bank. Promoting Nutrition Security in Haiti. 2010. URL: http: / / siteresources . worldbank . org /
NUTRITION/Resources/HaitiNutritionAssessmentEnglisl pdf.

[2] CIA. The World Factbook - GDP per Capita Ranking. 2015. URL: https: / / www.cia.gov/library/publications/ the-world-factbook/rankorder/2004rank . html ? countryname = Haiti \& countrycode = ha \& regioncode=cam\&rank=209\# ha.

[3] European Commission. Four years on from the Haiti earthquake: The EU's response. 2015. URL: http: / / europa. eu/rapid/press-release_MEMO-14-3_en.htm.

[4] Antonio Maria Delgado. Venezuela slashes oil shipments to Cuba, Caribbean in half. 2015. URL: http: / / www . miamiherald. com / news / nation-world/world/americas / venezuela/article16381898.html.

[5] Center for Economic and Policy Research. Chávez in Haiti, a Clear Alternative to the "International Community". 2013. URL: http: / / www. cepr.net/index.php/blogs / relief-and-reconstruction-watch/chavezin-haiti-a-clear-alternative-to-theinternational-community.

[6] The Economist. Feeding Haiti: A New Menu. 2013. URL: http: / / www . economist. com/news / americas / 21579875-government-tries-load-up-platespoorest-people-americas-new-menu.

[7] UN Foundation. Haiti Earthquake Response. 2015. URL: http: //www. unfoundation.org/who-we-are/impact/ our-impact/health-data-disaster-relief/ haiti-earthquake-response.html.

[8] John Michael Greer. The Long Descent: A User's Guide to the End of the Industrial Age. New Society Publishers, 2008. ISBN: 9780865716094. URL: http: / / books . google. com/books? id=UqTZAAAAMAAJ.

[9] Embassy of Canada in Haiti. Canada's Response to the Devastating Earthquake. 2015. URL: http: / / www . canadainternation gc.ca/haiti/engagement/earthquake-seisme. aspx?lang=eng.

[10] Rob Hopkins. The transition companion: Making your community more resilient in uncertain times. Chelsea Green Publishing, 2011.

[11] Lilly Irani et al. "Postcolonial Computing: A Lens on Design and Development". In: Proceedings of the SIGCHI Conference on Human Factors in Computing Systems. CHI '10. Atlanta, Georgia, USA: ACM, 2010, pp. 1311-1320. ISBN: 978-1-60558-929-9. DOI: $10.1145 / 1753326.1753522$. URL: http://doi .acm.org/10.1145/1753326 . 1753522 .

[12] Ian James. AP Interview: Haiti leader says Venezuela aid key. 2011. URL: http: / / cnsnews. com/news/article/ ap-interview-haiti-leader-says-venezuelaaid-key.

[13] Jake Johnston. Is USAID Helping Haiti to Recover, or US Contractors to Make Millions? 2015. URL: http : / / www . thenation.com/article/195673/usaid-helpinghaiti-recover-or-us-contractors - makemillions. 
[14] Scott D. Mainwaring, Michele F. Chang, and Ken Anderson. "Infrastructures and Their Discontents: Implications for Ubicomp". In: Ubicomp. Ed. by Nigel Davies, Elizabeth D. Mynatt, and Itiro Siio. Vol. 3205. Lecture Notes in Computer Science. Springer, 2004, pp. 418-432. ISBN: 3-540-229558.

[15] CBC News. Haiti's healing far from finished 5 years after deadly earthquake. 2015. URL: http: / / www. cbc. ca / news / world / haiti - s-healing-far-fromfinished-5-years-after-deadly-earthquake1.2897222 .

[16] Euro News. Haiti protesters call for 50 percent cut in fuel price. Online video clip. 2015. URL: http: / / www . euronews. com/2015/02/14/haiti-protesters-callfor-50-percent-cut-in-fuel-price/.

[17] Donald J. Patterson, Susan Elliott Sim, and Tosin Aiyelokun. "Overcoming Blind Spots in Interaction Design: A Case Study in Designing for African AIDS Orphan Care Communities". In: Information Technologies \& International Development 5.4 (2009). ISSN: 1544-7529. URL: http: / / itidjournal. org/itid/article/view/424/192.

[18] Ed Pilkington. "Haitians launch new lawsuit against UN over thousands of cholera deaths". In: The Guardian (2014). URL: http: / / www . theguardian . com/world/2014/ mar/11/haiti-cholera-un-deaths-lawsuit.

[19] Ken Richards. Venezuela Rubbishes Reports That Petro Caribe Is Floundering. 2015. URL: http : / / www . winnfm . com/news/local/11966-venezuela-rubbishesreports-that-petro-caribe-is-floundering.

[20] Global Health Justice Partnership The Transnational Development Clinic and Association Haïtienne de Droit de l'Environnement. Peacekeeping Without Accountability: The United Nations' Responsibility for the Haitian Cholera Epidemic. The Yale Law School and the Yale School of Public Health, 2013. URL: http: / / www. law. yale. edu / documents / pdf/Clinics/Haiti_TDC_Final_Report.pdf.

[21] NY Times. Oil Prices: What's Behind the Drop? Simple Economics. 2015. URL: http : / / www . nytimes . com / 2015/01/13/business/energy-environment/ oil-prices.html.

[22] Bill Tomlinson et al. "Collapse informatics and practice: Theory, method, and design". In: ACM Trans. Comput.-Hum. Interact. 20.4 (2013), 24:1 -24:26. DOI: 10 . 1145/2493431. URL: http: / / doi.acm.org/10.1145/2493431.

[23] Bill Tomlinson et al. "Collapse Informatics: Augmenting the Sustainability and ICT4D Discourse in HCI". In: Proceedings of the 2012 ACM annual conference on Human Factors in Computing Systems. CHI '12. Austin, Texas, USA: ACM, 2012, pp. 655-664. ISBN: 978-1-4503-1015-4. DOI: $10.1145 / 2207676.2207770$. URL: http: / / doi . acm.org/10.1145/2207676.2207770.

[24] Bill Tomlinson et al. "What if Sustainability Doesn't Work Out?" In: ACM Interactions 19.6 (Nov. 2012), pp. 50-55. ISSN: 1072-5520. DOI: $10.1145 / 2377783.2377794$. URL: http://doi.acm.org/10.1145/2377783. 2377794 .
[25] USAID. Fact Sheet: U.S. Assistance to Haiti Overview for 2010-2015. 2015. URL: http : / / www . usaid. gov / news-information/fact-sheets/us-assistancehaiti-overview-2010-2015-december-2014.

[26] Renee A. Vezina. "Combating Impunity in Haiti: Why the ICC Should Prosecute Sexual Abuse by UN Peacekeepers". In: Ave Maria International Law Journal 1.2 (2012), pp. 431460. URL: http: / / papers.ssrn. com/sol3/papers. cfm?abstract_id=2239478.

[27] Wikipedia. Foreign Aid to Haiti. 2015. URL: http: / / en. wikipedia.org/wiki/Eoreign_aid_to_Haiti. 